Article

\title{
Neutralizing Concentrations of Anti-Botulinum Toxin Antibodies Positively Correlate with Mouse Neutralization Assay Results in a Guinea Pig Model
}

\author{
Milan T. Tomic ${ }^{1, *}$, Shauna Farr-Jones ${ }^{2}{ }^{(}$, Emily S. Syar ${ }^{3}$, Nancy Niemuth ${ }^{3}$, Dean Kobs ${ }^{3}$, Michael J. Hackett ${ }^{3}$, \\ Yero Espinoza ${ }^{1}$, Zacchary Martinez ${ }^{1}$, Khanh Pham ${ }^{1}$, Doris M. Snow ${ }^{4}$, James D. Marks ${ }^{2}{ }^{10}$ and Ronald R. Cobb ${ }^{4}$ \\ 1 National Resilience, Inc., 2061 Challenger Dr., Alameda, CA 94501, USA; yero.espinoza@resilience.com (Y.E.); \\ zacchary.martinez@resilience.com (Z.M.); Khanh.pham@alector.com (K.P.) \\ 2 Department of Anesthesia and Perioperative Care, University of California, 1001 Potrero Ave., \\ San Francisco, CA 94110, USA; shauna.farr-jones@ucsf.edu (S.F.-J.); jim.marks@ucsf.edu (J.D.M.) \\ 3 Battelle Biomedical Research Center, West Jefferson, Columbus, OH 43162, USA; syare@battelle.org (E.S.S.); \\ niemuth@battelle.org (N.N.); dkobs@amplify-bio.com (D.K.); mike.hackett@gmail.com (M.J.H.) \\ 4 National Resilience, Inc., 13200 NW, Nano Ct, Alachua, FL 32615, USA; doris.snow@resilience.com (D.M.S.); \\ RonCobb76@yahoo.com (R.R.C.) \\ * Correspondence: milan.tomic@resilience.com; Tel.: +1-510-333-9387
}

check for updates

Citation: Tomic, M.T.; Farr-Jones, S.; Syar, E.S.; Niemuth, N.; Kobs, D.; Hackett, M.J.; Espinoza, Y.; Martinez,

Z.; Pham, K.; Snow, D.M.; et al.

Neutralizing Concentrations of Anti-Botulinum Toxin Antibodies Positively Correlate with Mouse Neutralization Assay Results in a Guinea Pig Model. Toxins 2021, 13, 671. https://doi.org/10.3390/ toxins13090671

\section{Received: 7 July 2021}

Accepted: 16 September 2021

Published: 21 September 2021

Publisher's Note: MDPI stays neutral with regard to jurisdictional claims in published maps and institutional affiliations.

Copyright: (C) 2021 by the authors. Licensee MDPI, Basel, Switzerland. This article is an open access article distributed under the terms and conditions of the Creative Commons Attribution (CC BY) license (https:/ / creativecommons.org/licenses/by/ $4.0 /)$.

\begin{abstract}
Botulinum neurotoxins (BoNT) are some of the most toxic proteins known and can induce respiratory failure requiring long-term intensive care. Treatment of botulism includes the administration of antitoxins. Monoclonal antibodies (mAbs) hold considerable promise as BoNT therapeutics and prophylactics, due to their potency and safety. A three-mAb combination has been developed that specifically neutralizes BoNT serotype A (BoNT/A), and a separate three mAb combination has been developed that specifically neutralizes BoNT serotype B (BoNT/B). A six mAb cocktail, designated G03-52-01, has been developed that combines the anti-BoNT/A and anti-BoNT/B mAbs. The pharmacokinetics and neutralizing antibody concentration (NAC) of G03-52-01 has been determined in guinea pigs, and these parameters were correlated with protection against an inhalation challenge of BoNT/A1 or BoNT/B1. Previously, it was shown that each antibody demonstrated a dose-dependent $\mathrm{mAb}$ serum concentration and reached maximum circulating concentrations within $48 \mathrm{~h}$ after intramuscular (IM) or intraperitoneal (IP) injection and that a single IM injection of G03-52-01 administered $48 \mathrm{~h}$ pre-exposure protected guinea pigs against an inhalation challenge of up to $93 \mathrm{LD}_{50} \mathrm{~s}$ of BoNT/A1 and $116 \mathrm{LD}_{50} \mathrm{~s}$ of BoNT/B1. The data presented here advance our understanding of the relationship of the neutralizing NAC to the measured circulating antibody concentration and provide additional support that a single IM or intravenous (IV) administration of G03-52-01 will provide pre-exposure prophylaxis against botulism from an aerosol exposure of $\mathrm{BoNT} / \mathrm{A}$ and BoNT/B.
\end{abstract}

Keywords: botulinum neurotoxin; botulism; aerosol; monoclonal antibody (mAb); guinea pig inhalation model; oligoclonal antibody; mouse neutralization assay (MNA); neutralizing antibody concentration (NAC)

Key Contribution: This paper demonstrates the correlation between the results of the mouse neutralization assay for anti-botulinum antibodies and the neutralizing antibody concentration in a guinea pig model of inhalational botulism.

\section{Introduction}

Botulism can be fatal if untreated and is caused by exposure to any one of the highly toxic protein family known as botulinum neurotoxins (BoNTs) [1-4], which are the most potent of all known biological poisons $[5,6]$. At least seven BoNT serotypes (A-G) have been reported [7-9]. An eighth serotype, BoNT/H has been reported [10], though its 
existence as a separate serotype is not universally agreed upon [11]. Serotypes are defined immunologically by the inability of the $\operatorname{IgG}$ antibodies that neutralize one serotype to neutralize the other serotypes [12]. BoNT serotypes A, B, E, and F cause the disease botulism in humans [13-15]. The majority of cases within the US are caused by BoNT/A and B, while worldwide, most botulism cases are caused by BoNT/A, B, and E, with BoNT/F being associated with a low incidence of food poisoning-related cases of botulism intoxication [1-4,13].

Due to the potential for use of BoNT by those of ill intent, the US Department of Defense has funded development of vaccines for BoNT/A and BoNT/B to protect warfighters from these serotypes [16]. An alternative to vaccination is prophylactic administration of safe recombinant human antibodies that neutralize BoNT [17-22]. Advantages of this passive immunization approach are that protection would be immediate and recipients would be able to receive therapeutic botulinum neurotoxin if needed subsequently [23].

The development of a potent human monoclonal antibody $(\mathrm{mAb})$ based drug product, G03-52-01, composed of multiple mAbs binding to non-overlapping epitopes on BoNT / A and BoNT/B has been described previously [17,19,20,24-26]. The BoNT/A [27], BoNT/B [28], BoNT/E (NCT03603665, unpublished results), and BoNT/C/D [29] antitoxins have completed Phase 1 testing in humans, without serious adverse side effects.

Botulinum toxin exposure can occur through a variety of routes, but inhalation is considered the most likely route in bioterrorism or biowarfare settings [30]. Therefore, an inhalational model of toxin exposure using the guinea pig has been developed [31]. The recombinant BoNT/A and BoNT/B antitoxins have been shown to be efficacious in inhalation botulism models in guinea pigs [26].

The primary objective of this study was to investigate the pharmacokinetic (PK) profiles of G03-52-01 following intramuscular (IM) or intravenous (IV) administration to guinea pigs and to evaluate the correlation between circulating antibody concentrations and the neutralizing antibody concentrations (NAC), measured using a mouse neutralization assay (MNA). Several MNA measurements are required to obtain the average NAC for a given sample. The levels of circulating anti-BoNT/A mAbs were assessed using an enzyme-linked immunosorbent assay (ELISA) [25]. The levels of circulating anti-BoNT/B mAbs were assessed using an electrochemiluminescence (ECL) assay [24].

Establishment of a correlation between the NAC and MNA would reduce the need for conducting multiple MNA studies during the development of these antibody drugs. The National Institute of Health (NIH) has identified finding alternatives to the use of animals for the BoNT mouse bioassay as a priority. The Scientific Advisory Committee on Alternative Toxicological Methods, which advises the Interagency Coordinating Committee on the Validation of Alternative Methods (ICCVAM) and the National Toxicology Program Interagency Center for the Evaluation of Alternative Methods (NICEATM), also considered the development and validation of alternatives to the mouse $\mathrm{LD}_{50}$ assay for BoNT potency testing a high priority [32]. Using a large number of animals for the efficacy/toxicity testing of botulinum toxins is also at odds with the concepts of reduction, replacement, and refinement, adopted by the European Union and the Organization for Economic Cooperation and Development, which suggests the development of alternative test methods that do not require animals for such studies [33].

\section{Results}

\subsection{Intravenous (IV) Administration of Anti-BoNT/A Antibodies}

All the IV administered antibodies in the anti-BoNT/A mAbs exhibited a biphasic curve consistent with 2-compartment kinetics through $168 \mathrm{~h}$ (7 days). The mAb concentration at the final timepoint at $336 \mathrm{~h}$ (14 days) was very low compared to the earlier timepoints for the XA-a and XA-c mAbs and did not fall on the biphasic curve (Figure 1); after $168 \mathrm{~h}$ there was a large increase in $\mathrm{mAb}$ clearance. As the kinetics of clearance change over time, the data could not be modeled compartmentally through $336 \mathrm{~h}$. The XA-a and XA-c antibodies could not be detected after $336 \mathrm{~h}$, suggesting an anti-drug antibody (ADA) 
response was likely generated against the mAbs. To fully characterize the PK properties, the data were modeled two ways: (1) the data through $168 \mathrm{~h}$ was fit to a 2-compartment model representing the intrinsic kinetics of the antibody without the putative ADA response, and (2) the data were fit to a non-compartmental model through $336 \mathrm{~h}$. The latter method provides the most accurate representation of exposure in the animal.
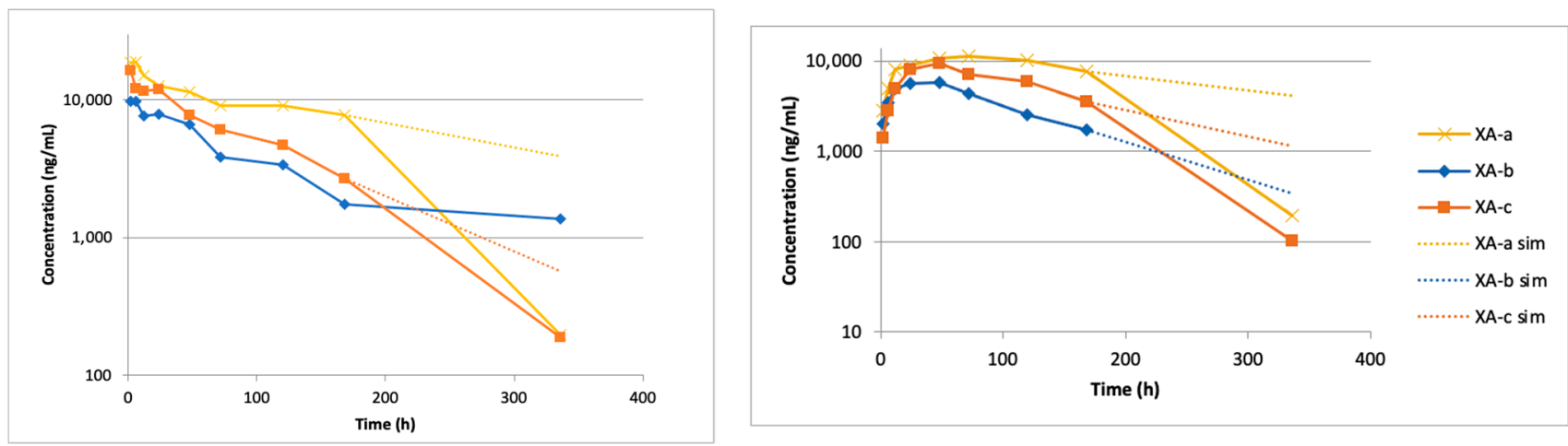

Figure 1. Concentration-time curves following IV (left) and IM (right) administration of $1.5 \mathrm{mg}$ total antibody XA-a, XA-b, and XA-c; solid lines represent ELISA-measured concentrations and dashed lines represent predicted concentrations based on noncompartmental analysis of the data through $168 \mathrm{~h}$.

The measured versus predicted concentration-time curve for XA-a, XA-b, and XA-c from the 2-compartment model is presented in Figure 2, and the derived parameters are presented in Table 1. While all the data fit a two-compartment model better than a onecompartment model, there was substantial variability between the curves. XA-a had a well-characterized distribution and elimination phase, with equilibrium being established by approximately $50 \mathrm{~h}$. XA-b had a much longer distribution phase, such that the first point on the terminal phase was at $168 \mathrm{~h}$. A concentration estimate for XA-b at $336 \mathrm{~h}$ was used to define the terminal phase. XA-c had an extremely fast distribution phase, such that the second timepoint at $6 \mathrm{~h}$ appears to be on the terminal phase. This made it difficult to accurately model the distribution phase, which led to a notably high estimate of $\mathrm{C}_{0}$ (the concentration immediately upon injection). The elimination rate half-lives $\left(\mathrm{t}_{\frac{1}{2}}\right.$ elim) estimated from this analysis were $201 \mathrm{~h}$ and $447 \mathrm{~h}$, for XA-a and XA-b, respectively. Since the XA-c was cleared much faster, its estimated elimination rate half-life was $14.8 \mathrm{~h}$. Despite the short elimination rate half-life, $\mathrm{mAb}$ concentrations could be measured through $336 \mathrm{~h}$. This is because the $\mathrm{mAb}$ distributes between compartments at a slower rate, thus limiting clearance. Consequently, the beta-phase half-life for XA-c was $73.5 \mathrm{~h}$. The beta-phase half-life is the slope of the terminal phase in a 2-compartmental model and is dependent on the rates of distribution between compartments, in addition to the elimination rate constant. The long half-lives resulted in large area under the curve (AUCs), of 5880, 6330, and $1430 \mathrm{~h}^{*} \mathrm{\mu g} / \mathrm{mL}$ for XA-a, XA-b, and XA-c, respectively. These AUC estimates are the result of an extrapolation through infinite time with no ADA. Thus, they should be considered overestimates of the exposures in smaller animals but may be more useful in extrapolating exposures to humans, where an ADA response is less likely. 


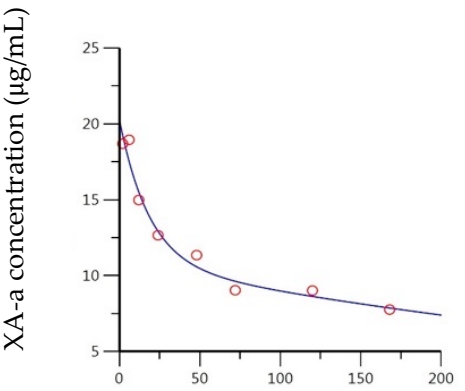

Time (h)

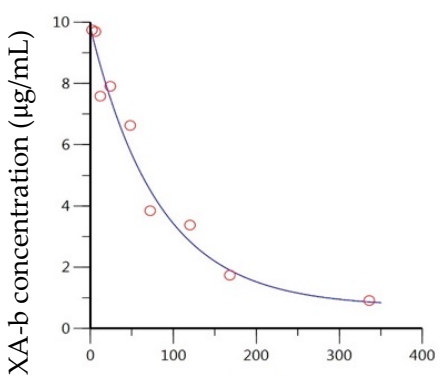

Time (h)

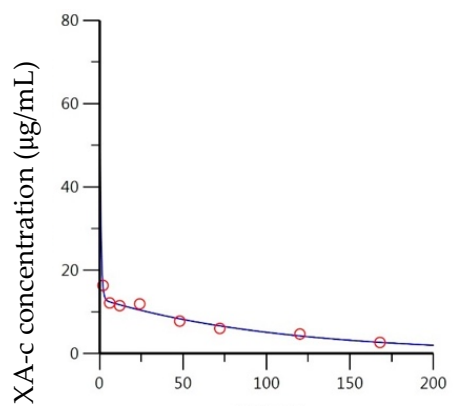

Time (h)

Figure 2. Concentration-time data for IV-administered XA-a, XA-b, and XA-c. Blue line indicates best line fit, based on a two-compartment model using Phoenix WinNonlin. A single point $(t=2 \mathrm{~h})$ represents the distribution phase for $\mathrm{XA}-\mathrm{c}$, which biased the model to a large $C_{0}$ of $66 \mu \mathrm{g} / \mathrm{mL}$.

Table 1. Pharmacokinetic parameters from compartmental analysis of anti-BoNT/A mAbs.

\begin{tabular}{|c|c|c|c|c|c|c|c|c|}
\hline $\mathbf{m A b}$ & $\begin{array}{c}\text { Dose } \\
\text { (mg/kg), } \\
\text { Route }\end{array}$ & Model & $\mathrm{C}_{0}(\mu \mathrm{g} / \mathrm{mL})$ & $\mathrm{T}_{\max }(\mathrm{h})$ & $\begin{array}{c}\beta \text {-Phase } \\
\mathbf{t}_{1 / 2}(h)\end{array}$ & $t_{1 / 2} \operatorname{Abs}(h)$ & $\begin{array}{l}\mathbf{t}_{1 / 2} \text { Elim } \\
\text { (h) }\end{array}$ & $\underset{\left(h^{*} \mu g / m L\right)}{\mathrm{AUC}_{\text {inf }}}$ \\
\hline XA-a & & 2-compartment & 20.3 & 0 & 365 & & 201 & 5880 \\
\hline$X A-b$ & $3, \mathrm{IV}$ & 2-compartment & 9.83 & 0 & 5200 & & 447 & 6330 \\
\hline XA-c & & 2-compartment & 66.9 & 0 & 73.5 & & 14.8 & 1430 \\
\hline XA-a & & 1-compartment & 11.2 & 55.4 & & 14.3 & 202 & 4000 \\
\hline$X A-b$ & 3, IM & 1-compartment & 5.97 & 29.9 & & 10.2 & 64.1 & 781 \\
\hline$X A-c$ & & 1-compartment & 9.07 & 42.0 & & 13.8 & 78.2 & 1480 \\
\hline
\end{tabular}

$\mathrm{C}_{0}$-the concentration immediately upon injection assuming instantaneous distribution throughout the central compartment; $\mathrm{t}_{1 / 2}$-half life; abs-absorption, elim —elimination; $\mathrm{AUC}_{\mathrm{inf}}$ —area under the curve from time zero extrapolated to infinity; Tmax — time for antibody to reach maximal concentration.

The full data set was analyzed using the non-compartmental model to provide a more accurate representation of the data that were measured, and the results are summarized in Table 2. The terminal phase half-life (i.e., the $\beta$-phase) was greatly decreased for XA-a and $X A-c$, due to the sharp reduction in concentrations at $336 \mathrm{~h}$, with respective half-lives of 35.2 and $34.4 \mathrm{~h}$. XA-b was less affected in the terminal phase estimation of $93.9 \mathrm{~h}$, due to the lack of a measurable concentration at $336 \mathrm{~h}$. $\mathrm{AUC}_{\text {last }}$ was used as the estimate of exposure for noncompartmental analysis, because the concentration dropped off rapidly for XA-a and $X A-c$, so there was no difference between $A U C_{\text {last }}$ and $A U C_{i n f}$. The concentration at $336 \mathrm{~h}$ allowed for significantly increased $\mathrm{AUC}_{\mathrm{inf}}$ for $\mathrm{XA}-\mathrm{b}$; without this data point the AUC $_{\text {inf }}$ for XA-b would have been well over $20 \%$ extrapolated. Thus, the estimates for $\mathrm{AUC}_{\text {last }}$ are 2410,1020, and $1390 \mathrm{~h}^{*} \mu \mathrm{g} / \mathrm{mL}$ for XA-a, XA-b, and XA-c, respectively.

Table 2. Pharmacokinetic parameters from noncompartmental analysis of anti-BoNT/A mAbs.

\begin{tabular}{|c|c|c|c|c|c|c|c|}
\hline $\mathrm{mAb}$ & $\begin{array}{l}\text { Dose } \\
\text { (mg/kg), } \\
\text { Route }\end{array}$ & $\begin{array}{c}\mathrm{C}_{\max } \\
(\mu \mathrm{g} / \mathrm{mL})\end{array}$ & $\begin{array}{c}\mathrm{T}_{\max } \\
\text { (h) }\end{array}$ & $\mathbf{t}_{1 / 2} \operatorname{Elim}(\mathbf{h})$ & $\begin{array}{c}\mathrm{AUC}_{\text {last }} \\
\left(\mathrm{h}^{*} \mu \mathrm{g} / \mathrm{mL}\right)\end{array}$ & $\mathbf{F}$ & $\begin{array}{c}\text { Simulated Concentration at } \\
336 \mathrm{~h} \text { Post-dose } \\
(\mathrm{g} / \mathrm{mL})\end{array}$ \\
\hline XA-a & & 18.9 & 6 & 35.2 & 2410 & & 3880 \\
\hline XA-b & 3, IV & 9.75 & 2 & 93.9 & 1020 & & - \\
\hline XA-c & & 16.4 & 2 & 34.4 & 1390 & & 569 \\
\hline XA-a & & 11.3 & 72 & 24.5 & 2260 & $94 \%$ & 4170 \\
\hline XA-b & $3, \mathrm{IM}$ & 5.76 & 48 & 73 & 627 & $83 \%$ & 344 \\
\hline XA-c & & 9.36 & 48 & 30.4 & 1370 & $99 \%$ & 1140 \\
\hline
\end{tabular}

$\mathrm{C}_{0}$-the concentration immediately upon injection assuming instantaneous distribution throughout the central compartment; $\mathrm{t}_{1 / 2}$-half life; elim-elimination; $\mathrm{AUC}_{\text {last }}$-area under the curve from time zero to last measurable timepoint; $\mathrm{T}_{\max }$-time for antibody to reach maximal concentration. 


\subsection{Pharmacokentics Following Intramuscular (IM) Administration of Anti-BoNT/A mAbs}

When the anti-BoNT/A mAbs were administered IM, all three mAbs exhibited a slow absorption phase followed by the elimination phase. In the case of all three $\mathrm{mAbs}$, a biphasic curve could not be seen after the $C_{\max }$, thus an extravascular one-compartment model provided a better fit for the data. Like the results observed with IV administration, all three of the mAbs could be modeled through $168 \mathrm{~h}$. At the next timepoint, $336 \mathrm{~h}, \mathrm{XA}-\mathrm{b}$ was not measurable while XA-a and XA-c showed an expedited clearance (Figure 1). The measured versus predicted concentration-time data for XA-a, XA-b, and XA-c, based on the compartmental model are provided in Figure 3. Based on the model, the respective estimates of the absorption half-life for XA-a, XA-b, and XA-c, were 14.3, 10.2, and $13.8 \mathrm{~h}$, which corresponded to $\mathrm{T}_{\max }$ values (time for antibody for reach maximum level) of 55.4, 29.9, and $42.0 \mathrm{~h}$. Estimates of the elimination half-life were 202, 64.1, and 78.2 h, respectively, for XA-a, XA-b, and XA-c. While the elimination rates for XA-a were very similar for both routes of administration, the elimination rate was lower for XA-b and greater for XA-c administered via IM, due to the limitations in fitting the models described above. Extrapolated estimates of AUC were determined to be 4000, 781, and $1480 \mathrm{~h}^{*} \mu \mathrm{g} / \mathrm{mL}$, respectively, for XA-a, XA-b, and XA-c.
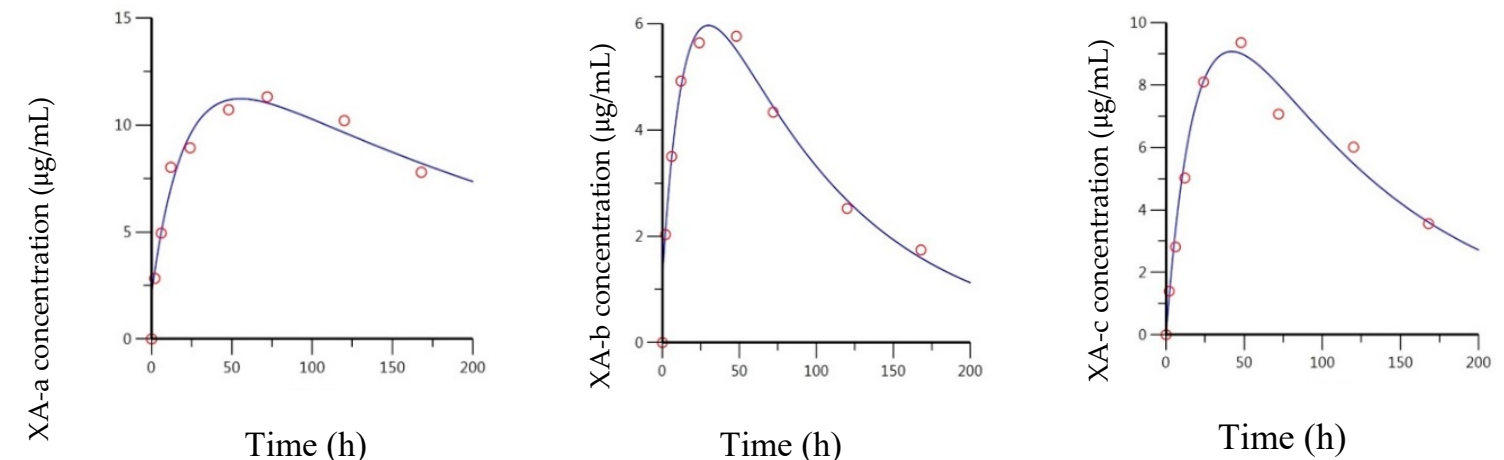

Figure 3. Concentration-time data for IM-administered XA-a, XA-b, and XA-c. Blue line indicates best fit, based on a one-compartment model using Phoenix WinNonlin.

Noncompartmental analysis of the IM concentration-time data resulted in terminal elimination half-life estimates of $24.5,73$, and $30.4 \mathrm{~h}$ for XA-a, XA-b, and XA-c, which agree with the compartmental estimates. However, the terminal elimination half-life of XA-a was underestimated substantially, due to the $336 \mathrm{~h}$ timepoint (Figure 3). Estimates for $\mathrm{AUC}_{\text {last }}$ were 2260, 627, and $1370 \mathrm{~h}^{*} \mu \mathrm{g} / \mathrm{mL}$ for XA-a, XA-b, and XA-c, respectively. Since the IM dose was equivalent to the IV dose, the ratio is also a reflection of the absolute bioavailability, F. Based on these estimates, XA-a was $94 \%$ bioavailable, XA-b was $83 \%$ bioavailable, and XA-c was $99 \%$ bioavailable. The lower estimate for XA-b is due in part to the lack of a value at the $336 \mathrm{~h}$ timepoint in the concentration-time curve following IM administration. However, the concentrations at $168 \mathrm{~h}$ were similar following both IM and IV administration of XA-b, due to the longer terminal half-life estimated following IV administration; thus, even if the AUC is extrapolated, it will not increase the bioavailability greatly.

\subsection{Pharmacokentics Following Intravenous (IV) Administration of Anti-BoNT/B mAbs}

The anti-BoNT/B mAbs exhibited less variability between constituent antibodies compared to the anti-BoNT/A mAbs and were more amenable to modeling. A biphasic curve is observed for all three mAbs. Additionally, the concentration-time curves suggest similar distribution and elimination rates for all the antibodies, as all curves are parallel; XB-a and XB-c are nearly superimposable (Figure 4). The kinetics appear to diverge from the model after $336 \mathrm{~h}$; however, the same phenomenon of rapidly decreasing concentrations is observed. The concentration-time data for the anti-BoNT/B mAbs were analyzed by 
fitting a two-compartment model through $336 \mathrm{~h}$, to determine the intrinsic PK parameters. Estimates of exposure and bioavailability were derived based on a non-compartmental model.
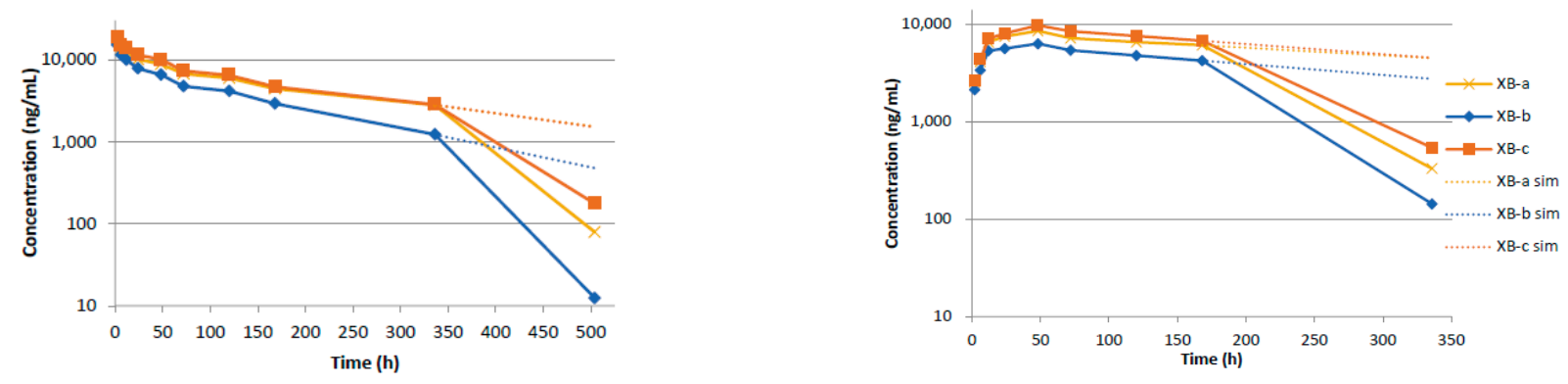

Figure 4. Concentration-time curves following IV (left) and IM (right) administration of $1.5 \mathrm{mg}$ total antibody XB-a, XB-b, and XB-c; solid lines represent ECL-measured concentrations. Dashed lines represent predicted concentrations, based on noncompartmental analysis of the data through $336 \mathrm{~h}$ (IV) or $168 \mathrm{~h}$ (IM).

The measured versus predicted concentration for all three anti BoNT/B mAbs is presented in Figure 5. All three models are nearly identical, with a clear distribution phase through $24 \mathrm{~h}$, before the terminal phase becomes apparent. Based on the model, XB-b appears to have a slightly decreased $\mathrm{C}_{0}$ of $17.2 \mu \mathrm{g} / \mathrm{mL}$, compared to $20.7 \mu \mathrm{g} / \mathrm{mL}$ for XB-a and XB-c. This is potentially due to a difference in dosing, as the entire XB-b curve is shifted slightly lower compared to the two other curves. The derived parameters from all three curves are in good agreement with each other (Table 2). Estimates of elimination half-life ranged from 59.4 to $81.1 \mathrm{~h}, \beta$-phase half-lives ranged from 115 to $144 \mathrm{~h}$, and AUC estimates ranged from 1470 to $2420 \mathrm{~h}^{*} \mu \mathrm{g} / \mathrm{mL}$ for each of the $\mathrm{XB}$ antibodies.

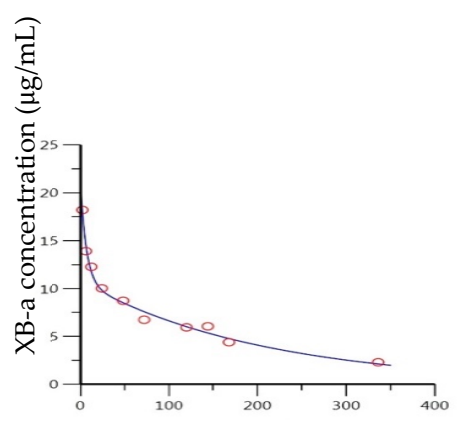

Time (h)

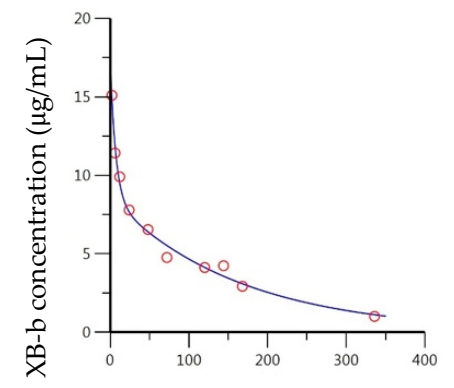

Time (h)

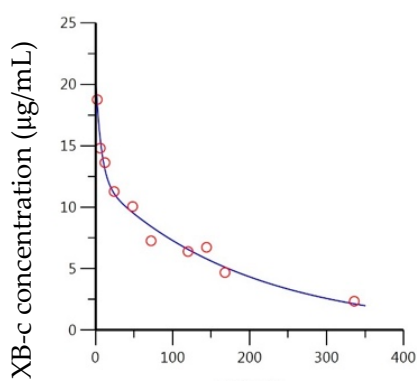

Time (h)

Figure 5. Predicted and observed concentration-time data for IV-administered XB-a, XB-b, and XB-c, based on a 2compartment model fit by Phoenix WinNonlin.

Noncompartmental analysis of the concentration-time data provided similar estimates to the compartmental model for IV administration. Since so many timepoints were used in the estimation of the terminal phase, the significantly lower concentration at $504 \mathrm{~h}$ of the $\mathrm{XB}$ mAbs (Figure 4) did not greatly affect estimates. Terminal phase half-lives of 69.5, 49.6, and 77.2 $\mathrm{h}$ were estimated for XB-a, XB-b, and XB-c, respectively. Similar estimates of exposure were also determined compared to the compartmental data; 2060, 1380, and $2220 \mathrm{~h}^{*} \mu \mathrm{g} / \mathrm{mL}$ for $\mathrm{XB}-\mathrm{a}, \mathrm{XB}-\mathrm{b}$, and $\mathrm{XB}-\mathrm{c}$, respectively.

\subsection{Pharmacokentics Following Intramuscular (IM) Administration of XB $m A$ As}

Following IM administration, the anti-BoNT/B mAbs were absorbed faster than the XA mAbs. Like the XA mAbs, after $C_{\max }$ a biphasic profile was not observed, thus a 1-compartment extravascular model fit the data better than a 2-compartment model. In addition, measurable concentrations were observed at $336 \mathrm{~h}$ for all three mAbs; however, 
the $168 \mathrm{~h}$ timepoint was again the inflection point for a change in clearance (Figure 4). Therefore, the data were modeled in the same manner as the anti-BoNT/A mAbs, with a compartmental model to estimate the intrinsic PK parameters and a noncompartmental analysis for measured values.

The measured versus predicted concentrations for all three mAbs are presented in Figure 6, and a summary of the PK parameters is provided in Tables 3 and 4 . All three mAbs exhibited very similar absorption and elimination profiles; again, with the XB-a and XB-c profiles essentially superimposed and the XB-b profile shifted slightly downward. The anti-BoNT/B mAbs were absorbed, approximately, twice as fast as the anti-BoNT/A mAbs, with absorption half-lives of $6.71,5.59$, and $8.08 \mathrm{~h}$, for XB-a, XB-b, and XB-c, respectively. The corresponding $\mathrm{T}_{\max }$ estimates were $36.1,31.0$, and $40.7 \mathrm{~h}$, respectively. Elimination half-lives were very consistent, with estimates of 254, 237, and $236 \mathrm{~h}$, respectively, for XB-a, $\mathrm{XB}-\mathrm{b}$, and $\mathrm{XB}-\mathrm{c}$, as reflected in the essentially parallel curves of Figure 6 . The resulting AUCs were also very similar; 3310, 2300, and $3570 \mathrm{~h}^{*} \mu \mathrm{g} / \mathrm{mL}$, for XB-a, XB-b, and XB-c, respectively.
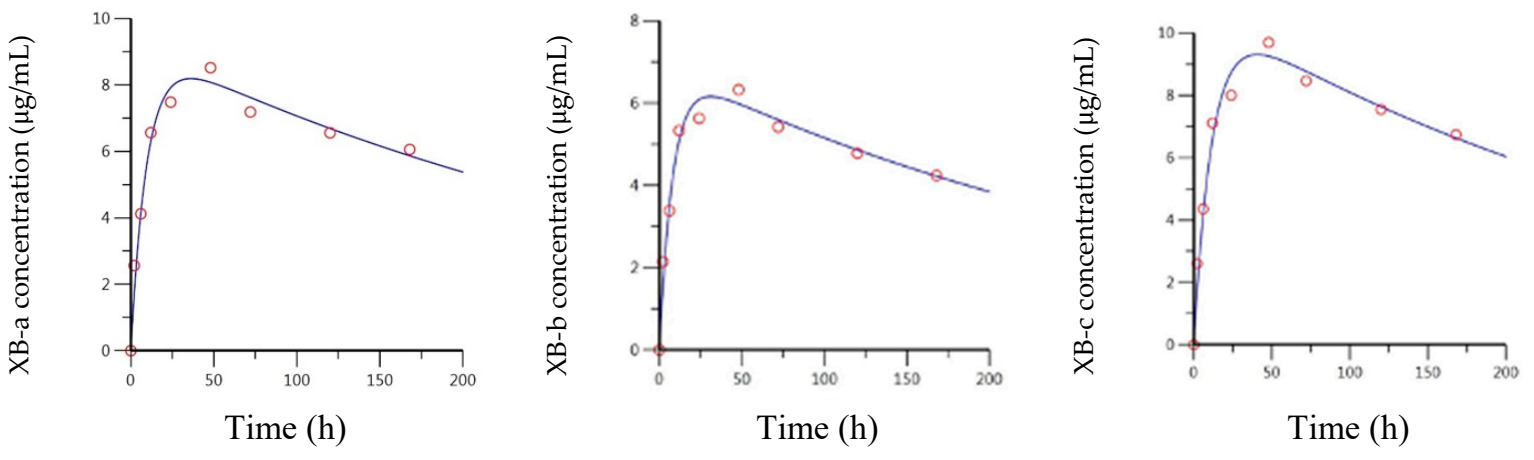

Figure 6. Predicted and observed concentration-time data for IM-administered XB-a, XB-b, and XB-c, based on a 2compartment model fit by Phoenix WinNonlin.

Table 3. Pharmacokinetic parameters from compartmental analysis of anti-BoNT/B mAbs.

\begin{tabular}{|c|c|c|c|c|c|c|c|c|c|}
\hline $\begin{array}{c}\text { Administration } \\
\text { Route }\end{array}$ & $\mathrm{mAb}$ & $\begin{array}{c}\text { Dose } \\
(\mathrm{mg} / \mathrm{kg})\end{array}$ & Model & $\begin{array}{c}\mathrm{C}_{0} \\
(\mu \mathrm{g} / \mathrm{mL})\end{array}$ & $\begin{array}{c}T_{\max } \\
\text { (h) }\end{array}$ & $\begin{array}{c}\beta \text {-Phase } \\
t_{1 / 2}(h)\end{array}$ & $\begin{array}{c}t_{1 / 2} A b s \\
\text { (h) }\end{array}$ & $\begin{array}{l}t_{1 / 2} \text { Elim } \\
\text { (h) }\end{array}$ & $\begin{array}{c}\text { AUC }_{\text {inf }} \\
\left(h^{*} \mu \mathrm{g} / \mathrm{mL}\right)\end{array}$ \\
\hline \multirow{4}{*}{ IV } & XB-a & & 2-compartment & 20.7 & 0 & 144 & & 77.1 & 2300 \\
\hline & $\mathrm{XB}-\mathrm{b}$ & 3 & 2-compartment & 17.2 & 0 & 115 & & 59.4 & 1470 \\
\hline & $\mathrm{XB}-\mathrm{C}$ & & 2-compartment & 20.7 & 0 & 133 & & 81.1 & 2420 \\
\hline & XB-a & & 1-compartment & 8.19 & 36.1 & & 6.71 & 254 & 3310 \\
\hline \multirow[t]{2}{*}{$\mathrm{IM}$} & $\mathrm{XB}-\mathrm{b}$ & 3 & 1-compartment & 6.16 & 31.0 & & 5.59 & 237 & 2300 \\
\hline & $\mathrm{XB}-\mathrm{C}$ & & 1-compartment & 9.3 & 40.7 & & 8.08 & 236 & 3570 \\
\hline
\end{tabular}

$\mathrm{C}_{0}$-the concentration immediately upon injection, assuming instantaneous distribution throughout the central compartment; $1.5 \mathrm{mg}$ total anti-BoNT/B mAbs administered $\mathrm{t}_{1 / 2}$-half life; elim—elimination.

Table 4. Pharmacokinetic parameters from non-compartmental analysis of anti-BoNT/B mAbs.

\begin{tabular}{|c|c|c|c|c|c|c|c|c|c|}
\hline $\begin{array}{c}\text { Administration } \\
\text { Route }\end{array}$ & $\mathrm{mAb}$ & $\begin{array}{c}\text { Dose } \\
(\mathrm{mg} / \mathrm{kg})\end{array}$ & $\begin{array}{c}C_{\max } \\
(\mu g / m L)\end{array}$ & $\mathrm{T}_{\max }(\mathrm{h})$ & $\begin{array}{l}t_{1 / 2} \text { Elim } \\
\text { (h) }\end{array}$ & $\begin{array}{c}\mathrm{AUC}_{\text {last }} \\
\left(\mathrm{h}^{*} \mu \mathrm{g} / \mathrm{mL}\right)\end{array}$ & $\begin{array}{l}F \\
(\%)\end{array}$ & $\begin{array}{c}\text { Simulated } \\
C_{336} \\
(\mu \mathrm{g} / \mathrm{mL})\end{array}$ & $\begin{array}{c}\text { Simulated } \\
\mathrm{C}_{504} \\
(\mu \mathrm{g} / \mathrm{mL})\end{array}$ \\
\hline \multirow{3}{*}{ IV } & XB-a & \multirow{3}{*}{3} & 18.2 & 2 & 69.5 & 2060 & & & 1040 \\
\hline & XB-b & & 15.1 & 2 & 49.6 & 1380 & & & 361 \\
\hline & XB-c & & 18.8 & 2 & 77.2 & 2220 & & & 1000 \\
\hline \multirow{3}{*}{ IM } & XB-a & \multirow{3}{*}{3} & 8.52 & 48 & 38.1 & 1670 & 81 & 4480 & \\
\hline & $\mathrm{XB}-\mathrm{b}$ & & 6.33 & 48 & 26.5 & 1210 & 88 & 2760 & \\
\hline & XB-C & & 9.69 & 48 & 46.3 & 1890 & 85 & 4520 & \\
\hline
\end{tabular}

$\mathrm{C}_{336} ; \mathrm{C}_{504}$ - concentration at 336 and $504 \mathrm{~h}$ post-dose, respectively; $1.5 \mathrm{mg}$ total anti-BoNT/B mAbs were administered; $\mathrm{C}_{\text {max }}$ - the maximal concentration; $\mathrm{T}_{\max }$ - time that maximal concentration is observed; $\mathrm{t}_{1 / 2}$ elim-elimination half-life; $\mathrm{AUC}_{\text {last }}$-area under the curve from time zero to last measurable timepoint; F-fraction absorbed. 
Due to the sharp decrease in concentration for all three mAbs at $336 \mathrm{~h}$, the estimated terminal phase half-lives were greatly reduced in the noncompartmental analysis. For XB-a, XB-b, and XB-c, estimates of 38.1, 26.5, and $46.3 \mathrm{~h}$ were calculated, which were approximately 5- to 8-fold lower than those estimated from the compartmental analysis. Corresponding $\mathrm{AUC}_{\text {last }}$ estimates were 1670, 1210, and $1890 \mathrm{~h}^{*} \mathrm{\mu g} / \mathrm{mL}$. When these estimates of exposure were compared to those for IV, bioavailability estimates of $81 \%, 88 \%$, and $85 \%$ were calculated for XB-a, XB-b, and XB-c, respectively. These estimates are similar but slightly lower than those for the anti-BoNT/A mAbs.

\subsection{Correlation of Pharmacokinetics and MNA for Anti-BoNT/A and /B mAbs}

The concentration of the mAbs measured by ELISA or ECL was compared with that measured by MNA. Blood samples were collected at 6, 12, 24, 48, and $336 \mathrm{~h}$ (14 days) post-dosing, following either IV or IM administration. After anti-BoNT/A mAb IM administration, the NAC increased from 5.3 Units $/ \mathrm{mL}$ at $6 \mathrm{~h}$ to 19 Units $/ \mathrm{mL}$ at $48 \mathrm{~h}$ postadministration and then decreased to less than 0.14 Units $/ \mathrm{mL}$ at $336 \mathrm{~h}$ (Figure 7 ). The NAC $6 \mathrm{~h}$ after anti-BoNT/A mAb IV administration was $16 \mathrm{Units} / \mathrm{mL}$ and remained elevated at $12 \mathrm{~h}, 24 \mathrm{~h}$, and $48 \mathrm{~h}$, with values of 17,12 , and $20 \mathrm{Units} / \mathrm{mL}$, respectively, before decreasing to 1.4 Units $/ \mathrm{mL}$ at $336 \mathrm{~h}$. For anti-BoNT/B mAbs administered IM, the average NAC increased, from $10 \mathrm{Units} / \mathrm{mL}$ at $6 \mathrm{~h}$ to $30 \mathrm{U} / \mathrm{mL}$ at $24 \mathrm{~h}$. The NAC remained at $29 \mathrm{Units} / \mathrm{mL}$ at $48 \mathrm{~h}$ and decreased to less than $0.45 \mathrm{Units} / \mathrm{mL}$ at $336 \mathrm{~h}$. The anti-BoNT/B mAbs administered IV had a NAC of 31 Units/mL at $6 \mathrm{~h}$ post-administration. Overall, the NAC per group remained elevated at 12, 24, and $48 \mathrm{~h}$, with values of 39, 23, and 33 Units/mL, respectively. The NAC decreased to less than $5.3 \mathrm{Units} / \mathrm{mL}$ at $336 \mathrm{~h}$.

Table 5. Parameters from linear regression and correlation of individual mAb concentration from ELISA or ECL vs. neutralizing antibody concentration (NAC).

\begin{tabular}{|c|c|c|c|c|c|c|c|c|}
\hline & XA-a & XA-b & XA-c & $\begin{array}{c}\text { All } 3 \text { Anti-A } \\
\text { mAbs }\end{array}$ & XB-a & XB-b & XB-c & $\begin{array}{c}\text { All } 3 \text { Anti-B } \\
\text { mAbs }\end{array}$ \\
\hline $\begin{array}{l}\text { Best fit Slope } \\
\quad(95 \% \mathrm{CI})\end{array}$ & $\begin{array}{c}815.7 \\
(614.0-1017)\end{array}$ & $\begin{array}{c}453.8 \\
(335.9-571.8)\end{array}$ & $\begin{array}{c}618.9 \\
461.4-776.5)\end{array}$ & $\begin{array}{c}1888 \\
(1428-2349)\end{array}$ & $\begin{array}{c}324.8 \\
(302.8-346.9)\end{array}$ & $\begin{array}{c}253.6 \\
(234-273.1)\end{array}$ & $\begin{array}{c}358.3 \\
(335.3-381.3)\end{array}$ & $\begin{array}{c}880.3 \\
(694.8-1066)\end{array}$ \\
\hline Goodness of fit & 3855 & 2289 & 3011 & 8064 & 2169 & 1922 & 2261 & 6605 \\
\hline $\mathrm{R}^{2}$ & 0.6934 & 0.5765 & 0.6795 & 0.6949 & 0.8012 & 0.7659 & 0.8210 & 0.7436 \\
\hline$p$ value & 0.0028 & 0.0176 & 0.0036 & 0.0027 & 0.0005 & 0.0009 & 0.0003 & 0.0013 \\
\hline
\end{tabular}

CI: Confidence interval. Linear regression and correlation calculated with Prism v9.0. The 0,0 data point included. Correlation was calculated using the average of replicates.
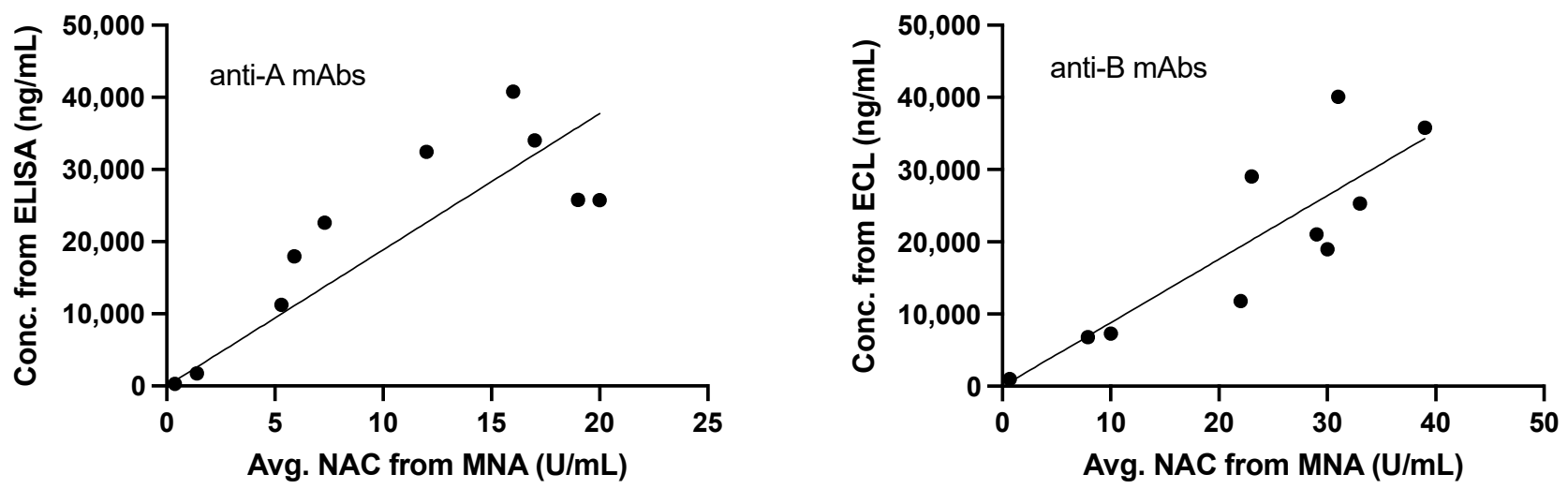

Figure 7. Comparison of anti-BoNT/A and /B mAbs average concentrations measured by ELISA or ECL and MNA. Measurements from animals dosed via IM and IV are combined for this analysis. The line was calculated from regression and included the 0,0 datapoint. Regression and correlation parameters are shown in Table 5. 
Since the serum drug concentration is independent of the route of administration, the antibody concentrations at each timepoint were compared to the average NAC from both IV and IM assays. Total antibody concentrations (XA-a, XA-b, and XA-c, or XB-a, XB-b, and $\mathrm{XB}-\mathrm{c})$ at each timepoint, as determined using ELISA or ECL, respectively, were compared to the average NAC. The NAC values and mAb concentration values were then plotted. The individual $\mathrm{mAb}$ concentrations correlated well with the average $\mathrm{NAC}$, indicating a linear correlation between circulating antibody and the protection observed, as measured by the NAC (Figure 8). For all mAbs, the slope was significantly different from zero, $p<0.0001$ and the correlations were significant (alpha $=0.05)$. Parameters from linear regression analyses are shown in Table 5 . The $\mathrm{R}^{2}$ for XA-a was 0.6934 , for XA-b was 0.5765 , and for $X A-C$ was 0.6795 . The correlation between average NAC and MNA was stronger for the anti-B mAbs. The $\mathrm{R}^{2}$ for XB-a was 0.8012 , for XB-b was 0.7659 , and for XB-c was 0.821 .
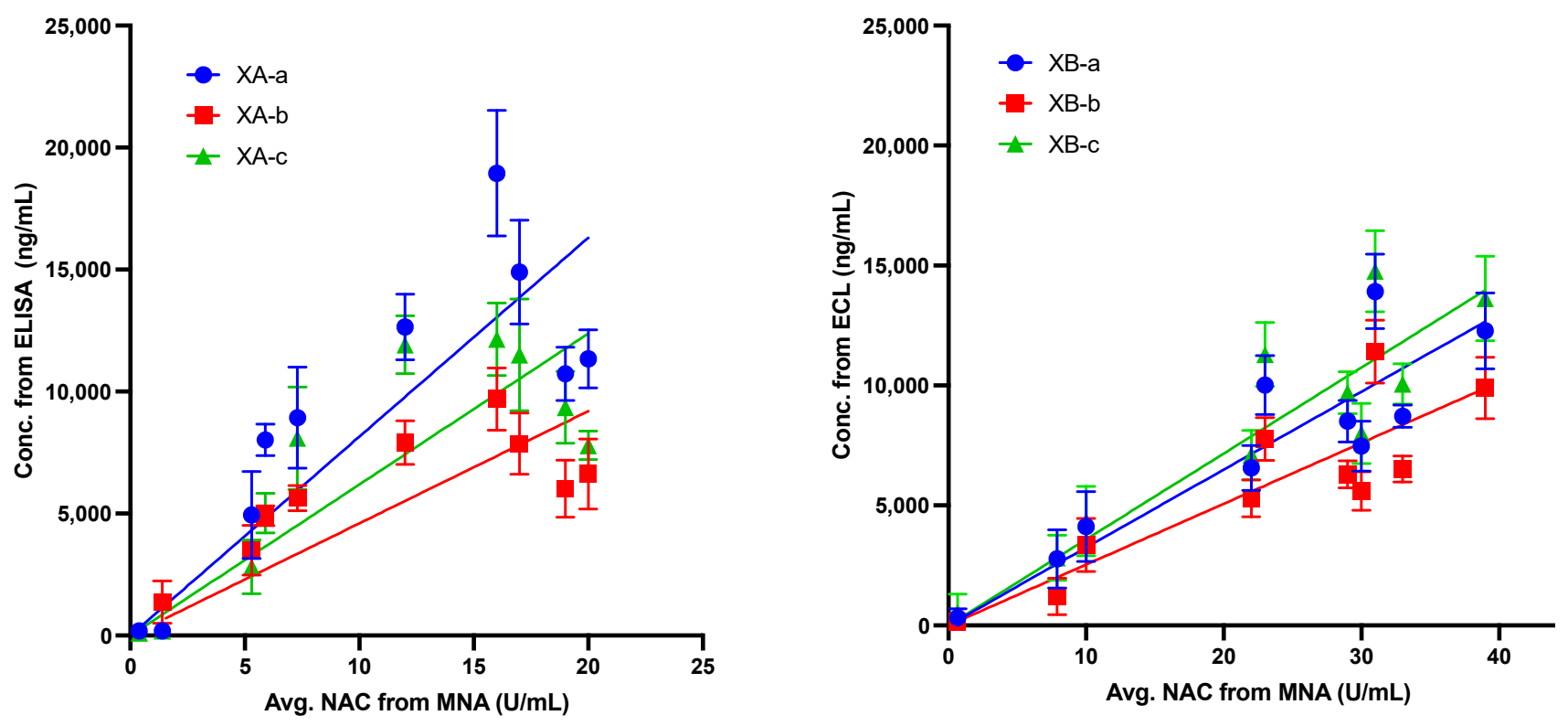

Figure 8. Comparison of individual anti-BoNT/A and B mAbs concentrations measured by ELISA or ECL and average (avg.) neutralizing antibody concentration (NAC) from the mouse neutralization assay (MNA). Measurements from animals dosed via IM and IV are combined for this analysis. The line was calculated from regression and included the 0, 0 datapoint. Regression and correlation parameters are shown in Table 5. Error bars indicate standard deviation. Linear regression and correlation were calculated with Prism v9.0. 0, 0 data point included.

The average NAC is a result of the three circulating antibodies, due to the mechanism of action [17], thus the concentrations of the three anti-BoNT/A and anti-BoNT/B were averaged and plotted against the average NAC to determine the correlation (Figure 7). As the average NAC increases, the molecular concentration increases, establishing a significant correlation between the circulating antibody concentration and protection, indicated by the average NAC observed. For both anti-A and anti-B mAbs, the slope is significantly different from zero, $p<0.0001$ and the correlations are significant (alpha $=0.05$ ).

It was previously shown that the concentration of each of the six antibodies that comprise G03-52-01 demonstrate peak or near-peak mAb serum concentrations $48 \mathrm{~h}$ after IM injection in guinea pigs [26] and that the antibody concentrations of each of the antibodies could be detected up to 28 days post-IM injection. Here, we found NAC up to 14 days postIM injections, with doses of $1.5 \mathrm{mg} /$ animal for anti-BoNT/A and $1.5 \mathrm{mg}$ of anti-BoNT/B $\mathrm{mAbs}$, which are correlated with the efficacy and mouse NAC determinations.

\section{Discussion}

Botulism is a neuroparalytic syndrome that can progress to respiratory failure and death without rapid treatment [34]. Passive immunization against botulism can be achieved 
by administering neutralizing antibodies [35-37]. The only FDA approved therapies, polyclonal antibodies such as botulinum immune globulin (BIG-IV) [38] and BAT ${ }^{\circledR}$ [39], have severe limitations $[40,41]$ that can be overcome by recombinant mAbs.

MNA is the gold standard method for determining the potency of an antitoxin and is used to demonstrate the NAC for a given sample [42]. However, the mouse bioassay requires hundreds of animals a week to perform, is expensive, and is subject to the significant variability inherent in a bioassay. Thus, a more rapid in vitro method to determine the potency of antitoxin mAbs would be a considerable advance in the development of these antibody drugs.

Here, we correlated the MNA and the average NAC measured with the circulating antibody concentration for anti-BoNT/A and anti-BoNT/B mAbs delivered via IM and IV. Comparison of the NAC and measured circulating antibody concentration allows for the establishment of a correlation between the presence of antibody in the sera and the NAC. Circulating antibodies, as determined by ELISA or ECL, and neutralizing antibodies, as determined by the MNA, reached a peak concentration in guinea pigs within $48 \mathrm{~h}$ post-administration, and the correlation with the average NAC measured demonstrates the causative effect of the antibodies in circulation. This correlation provides evidence in support of the use of circulating antibody concentration as measured by ECL or ELISA as a replacement for the MNA.

All the anti-BoNT/B antibodies exhibited a dramatic change in kinetics between 336 and $504 \mathrm{~h}$ (Figure 4), when the long terminal half-lives that are characteristic of mAbs abruptly decreased. The timing and effect on the concentration-time profile is consistent with an ADA response that occurred at approximately the same time and was independent of the route of administration. While we did not measure ADA in the guinea pig, we did measure ADA in rat [43]. There is no expectation that guinea pigs would be unique in not generating ADA. The effect of ADA would be to reduce the drug antibodies from circulation and because they would not bind to toxin, they would not interfere with the ECL or ELISA. From the PK analysis, the anti-BoNT/A mAbs exhibited a greater physiological variability than the anti-BoNT/B mAbs. Each of the six IgG1 antibodies studied here has the same constant region, with different variable regions. The reason for the variation in PK for each antibody is unknown. This can be seen in the widely variable distribution phases following IV administration, as shown in Figure 2. The same was observed following IM injection of the anti-BoNT/A mAbs (Figure 3). The absorption and elimination profiles are variable for each antibody, resulting in three dissimilar curves. Due to this, the exposure to each antibody was highly variable: $1020-2410 \mathrm{~h}^{*} \mathrm{\mu g} / \mathrm{mL}$ (IV, non-compartmental analysis), $1430-6330 \mathrm{~h}^{*} \mu \mathrm{g} / \mathrm{mL}$ (IV, compartmental analysis), 627-2260 h* $\mu \mathrm{g} / \mathrm{mL}$ (IM, noncompartmental analysis), and $781-4000 \mathrm{~h}^{*} \mu \mathrm{g} / \mathrm{mL}$ (IM, compartmental analysis). The concentration-time profiles for anti-BoNT/B mAbs, on the other hand, were nearly superimposable following both IV and IM administration (Figure 4). The XB-b profile was consistently below the other two curves, but resulted in similar $\mathrm{C}_{\max }$ and AUC estimates, independently of the route of administration or method of analysis.

\section{Conclusions}

This work continues previous efficacy investigations with three antibody combinations to BoNT serotypes $\mathrm{A}$ and $\mathrm{B}$, which were shown to completely protect guinea pigs against lethal aerosolized doses of BoNT/A and BoNT/B [26]. To protect against BoNT/A and BoNT/B intoxication, a single cocktail of antibodies has been co-formulated in a lyophilized presentation, delivered IM for ease and speed of delivery.

The statistically significant correlation of the circulating antibody concentration with the serum NAC has been demonstrated in this study. Limitations of the MNA for PK modeling include intrinsic variability of the assay, high cost, long assay time, and the requirement for large numbers of animals. This study provides evidence to support the use of the measurement of the circulating antibody concentration as a surrogate for the MNA. 


\section{Materials and Methods}

\subsection{Antibodies}

An oligoclonal mixture of six IgG monoclonal antibodies (mAbs) against BoNT/A and BoNT/B, G03-52-01, comprised of a lyophilized, equimolar mixture of mAbs XA-a, XA-b, XA-c, and mAbs XB-a, XB-b, XB-c [24-28,44].

\subsection{Animals and Animal Welfare}

For the PK studies, a total of 108 male and female guinea pigs (Cavia porcellus, Crl: [HA]Br) purchased from the Charles River Laboratory were used. Guinea pigs were individually housed, with ad lib PMI, Inc., guinea pig chow and water, as previously described [36], except that a $12 \mathrm{~h}$ light-dark cycle was used. At the end of the study guinea pigs were euthanized by $\mathrm{CO}_{2}$ gas.

For the MNA studies, 240 male CD-1 (ICR) mice (Mus musculus) purchased from the Charles River Laboratory and weighing 17 to $23 \mathrm{~g}$ were used. Mice were individually housed with ad lib PMI, Inc. rodent chow and water under the same conditions as the guinea pigs. Mice that survived the $96 \pm 2$-h post-challenge observation period were euthanized by $\mathrm{CO}_{2}$ gas.

The research was conducted in compliance with the Animal Welfare Act (AWA, 7 U.S.C. §2131, 2002, 2007, and 2008) and other federal statutes and regulations relating to animals and experiments involving animals and adhered to the principles stated in the Guide for the Care and Use of Laboratory Animals (Battelle Biomedical Research Center, Columbus, OH, USA, Protocol Number 91734, approved 6 December 2017). Battelle Biomedical Research Center provides the only FDA approved, statistically validated MNA for determining anti-BoNT antibody concentrations (NACs) in the United States [16]. All animal procedures were conducted under protocols approved by the Institutional Animal Care and Use Committees (IACUC) of Battelle Biomedical Research Center, in accordance with IACUC guidelines [45]. General procedures for animal care and housing were in accordance with the Association for Assessment and Accreditation of Laboratory Animal Care International (AAALAC) recommendations.

\subsection{Pharmacokinetics (PK)}

PK profiles of circulating anti-BoNT/A antibodies were assessed using an enzymelinked immunosorbent assay (ELISA). The levels of circulating Anti-BoNT/B antibodies were assessed using an electrochemiluminescence (ECL) assay, as described [26]. Guinea pigs (Cavia porcellus, Crl: [HA]Br) were studied in three cohorts, PBS, G03-52-01 at doses of $3 \mathrm{mg}$ /animal delivered by IM or IV. A total of 108 male and female guinea pigs were used (12 controls, 48 each for IV and IM administration of G03-52-01). Samples were analyzed for PK with the ECL or ELISA assay at timepoints of 2 h, 6 h, 12 h, 24 h, 48 h, 72 h, 120 h, 168 h, $336 \mathrm{~h}, 504 \mathrm{~h}, 672 \mathrm{~h}, 840 \mathrm{~h}, 1008 \mathrm{~h}, 1344 \mathrm{~h}$, and $1680 \mathrm{~h}$. Due to the large volume of samples required to perform the MNA, samples were analyzed at timepoints of $0,6,12,24,48 \mathrm{~h}$, and 14-day post-antibody dose using the MNA. The amount of toxin neutralization afforded by the antibodies NAC was assessed using the MNA with BoNT/A1 and BoNT/B1, with concomitant ECL/ELISA mAb concentration measurements for the PK.

\subsection{Electrochemiluminescence (ECL) Assay for Anti-BoNT/B mAbs}

The levels of circulating Anti-BoNT/B antibodies, XB-a, XB-b, and XB-c, were assessed using an electrochemiluminescence (ECL) assay. The ECL method to measure mAb concentration in guinea pig serum is based on a bridging immunoassay using the Meso Scale Discovery (MSD) electrochemiluminescence (ECL) format $[26,27,44]$. The antibody specific domains used are recombinant domains of BoNT/A or /B [24,25]. Biotinylated and ruthenylated domains were used as the capturing and detecting reagents for the assay, respectively. The assay uses the bivalent binding capability of the antibodies to form a bridging complex with biotinylated domain and ruthenylated domain to generate ECL signals for the measurement of the target antibody concentration in serum. 
Briefly, a solution of reaction mixture containing both biotinylated domain and ruthenylated domain plus either calibration standards, assay acceptance controls, or study samples was incubated for $1 \mathrm{~h}$ at room temperature on an orbital shaker and shielded from light. The calibration standards and assay acceptance controls were prepared using drug products G03-52-01 containing six mAbs XA-a, XA-b, XA-c, XB-a, XB-b, and XB-c [24,25]. The standards were prepared by spiking G03-52-01 into neat guinea pig serum to make the highest concentration standard sample at $500 \mathrm{ng} / \mathrm{mL}$ ( $1 \mathrm{X}$ assay concentration). The subsequent standard points were prepared as described [26].

Three separate assay methods were used to measure concentrations of the antiBoNT/B mAbs, XB-a, XB-b, and XB-c in guinea pig serum. In each method standards, controls, and samples were diluted at the minimum required dilution of 1:20, with some samples being further diluted into the standard curve range. Each diluted standard, control, and sample was then combined with a solution containing the biotin labeled and ruthenium labeled forms of one of three recombinant domains of BoNT/B in a 96-well polypropylene plate and incubated for 12 to $18 \mathrm{~h}$ at room temperature on a shaker shielded from light. Once this incubation had been completed samples were transferred from the polypropylene plate to a streptavidin plate blocked with Blocking Buffer and incubated for an additional $2 \mathrm{~h}$ at room temperature on the shaker. The plate was washed and $2 \mathrm{X}$ read buffer was added to the plate before reading on the MSD Meso QuickPlex SQ 120.

The MSD instrument detected the chemiluminescent signal generated when an electric current was applied. The resulting signal was measured in ECL units. The calibration curve was plotted using a 4-parameter logistic curve fit using $1 / \mathrm{y}^{2}$ weighting. The concentrations of each analyte in the quality control $(\mathrm{QC})$ and study samples were interpolated from the calibration curve generated.

\subsection{ELISA Assay for Anti-BoNT/A mAbs}

Three separate enzyme-linked immunosorbent assay (ELISA) methods were used to measure concentrations of the BoNT/A mAbs, XA-a, XA-b, and XA-c in guinea pig serum, as previously described [25] with modifications. In the XA-a, XA-b, and XA-c assay, the domains were coated at concentrations of $1.0 \mu \mathrm{g} / \mathrm{mL}, 20.0 \mu \mathrm{g} / \mathrm{mL}$, and $5.0 \mu \mathrm{g} / \mathrm{mL}$; these are recombinant domains of botulinum toxin A. Nunc Maxisorp 96-well plates are used in each assay. After a coat incubation period of 12-24 h, each plate was washed and blocked for 1-4 h. Standards, controls, and samples were diluted at the minimum required dilution of 1:20, with some samples being further diluted into the standard curve range. Diluted standards, controls, and samples were added to the coated and blocked plate for three hours at room temperature on a shaker. During sample incubation, the XA-a, XA-b, and XA-c antibodies in guinea pig serum bind with the coated domains. The plate was then washed and goat anti-human $\operatorname{IgG}(\mathrm{H}+\mathrm{L})-\mathrm{HRP}$ was added to the plate and incubated for an additional hour. The plate was washed and $3,3^{\prime}, 5,5^{\prime}$-Tetramethylbenzidine (TMB) substrate solution was added to the plate and incubated in the dark for approximately $20 \mathrm{~min}$ before the addition of stop solution. The plate was read on a microplate reader at $450 \mathrm{~nm}$ for detection and $630 \mathrm{~nm}$ for reference.

A calibration curve was generated from the resulting absorbance values and plotted using a 4-parameter logistic curve fit using $1 / \mathrm{y}^{2}$ weighting. The concentrations of each analyte in the QCs and study samples were interpolated from the calibration curve generated.

\subsection{Measurement of Neutralizing Antibody Concentration (NAC) and Mouse Neutralization Assay (MNA)}

NACs were determined using a standardized and statistically-validated MNA based on methods developed by Cardella and Hatheway and Dang [46,47], as described previously [26]. Male CD-1 (ICR) mice (Mus musculus) purchased from the Charles River Laboratory and weighing 17 to $23 \mathrm{~g}$ were used for the MNA. A total of 240 mice were used (five timepoints $\mathrm{x}$ ten mice per group $\mathrm{x}$ two serotypes $\mathrm{x}$ two routes of administration, plus controls). The BoNT challenge materials were dilutions of the complex form of BoNT/A 
subtype A1 and BoNT/B subtype B1 purchased from Metabiologics (Madison, WI, USA). The BoNT/A1 was produced from a C. botulinum Hall A strain. The BoNT/B1 was produced from the $C$. botulinum Okra strain. BoNT and samples for the mouse neutralization assays (MNA) were diluted in $30 \mathrm{mM}$ phosphate buffered saline (PBS, $\mathrm{pH}$ 6.2) containing $0.2 \%(w / v)$ gelatin. Eight, four-fold dilutions were prepared for each serum sample. The antitoxin reference standards and guinea pig serum samples were titrated against a fixed amount of BoNT (31 mouse $\mathrm{LD}_{50} / \mathrm{mL}$ for BoNT/A1 and 19 mouse $\mathrm{LD}_{50} / \mathrm{mL}$ for BoNT/B1), incubated for 60 to $120 \mathrm{~min}$ at room temperature and $0.2 \mathrm{~mL}$ was injected IP into mice. The NAC was calculated as the ratio of the effective dose at which $50 \%$ of the animals survived $\left(\mathrm{ED}_{50}\right)$ of the standard curve, over the $\mathrm{ED}_{50}$ of the test curve.

\subsection{Statistical Methods}

For each MNA, probit analysis was used to fit a dose-response curve to the proportion of mice dead as a function of the base 10 logarithm of the antibody concentration. The NAC for each sample was estimated from the probit curves for the samples and associated reference standard. The $\mathrm{ED}_{50}$ of the associated standard was divided by the $\mathrm{ED}_{50}$ for the assay corresponding to the test sample.

For assays that failed due to excessive mortality, sample-specific lower limits of quantitation (LLOQs) were derived from hypothetical MNAs, in which the test curve just met the assay acceptance criteria and had the largest $\mathrm{ED}_{50}$ obtainable within the range of antibody concentrations tested. The observed standard curve $\mathrm{ED}_{50}$ (from the standard curve run concurrently with the test sample) was also incorporated, to allow for day-to-day variation in the performance of the assay. Thus, the LLOQ was calculated as the observed standard curve $\mathrm{ED}_{50}$ divided by the hypothetical test curve $\mathrm{ED}_{50}$. An adjusted NAC was then calculated with a value equal to one-half the LLOQ for the test curve.

The arithmetic mean was calculated for each BoNT serotype, dose route, and control or treatment group. To determine the average NAC per group, the sum of the individual NACs was divided by the total number of assays that passed the assay control acceptance criteria.

Linear regression and correlation analysis was performed using Prism 9.0 (GraphPad Software LLC, San Diego, CA). The data point at 0.0 was included in the linear regression. Pearson correlation and two-tailed $p$ values were calculated using Prism 9.0.

Author Contributions: M.T.T. funding acquisition, designed experiments, analyzed data, and wrote and edited manuscript; E.S.S., N.N., D.K., Y.E., Z.M., K.P. performed experiments and analyzed data; R.R.C. funding acquisition, designed experiments, analyzed data, and wrote and edited the manuscript; D.M.S. designed experiments, analyzed data, and edited manuscript; M.J.H. analyzed data; S.F.-J.-Wrote and edited the manuscript and analyzed data, and J.D.M. edited the manuscript. All authors have read and agreed to the published version of the manuscript.

Funding: This research was funded by a contract from the Joint PEO Chemical and Biological Defense DOD-Army-USASC, contract number W15QKN1691002.

Institutional Review Board Statement: Not applicable.

Informed Consent Statement: Not applicable.

Data Availability Statement: We have not disclosed the sequences of the antibodies described here because their intended use is for biodefense. All other data is included in this manuscript.

Conflicts of Interest: The authors of this paper are either employees of National Resilience, Inc. or were paid by National Resilience, Inc via this contract to perform this work. The funders had no role in the design of the study; in the collection, analyses, or interpretation of data; in the writing of the manuscript, or in the decision to publish the results. 


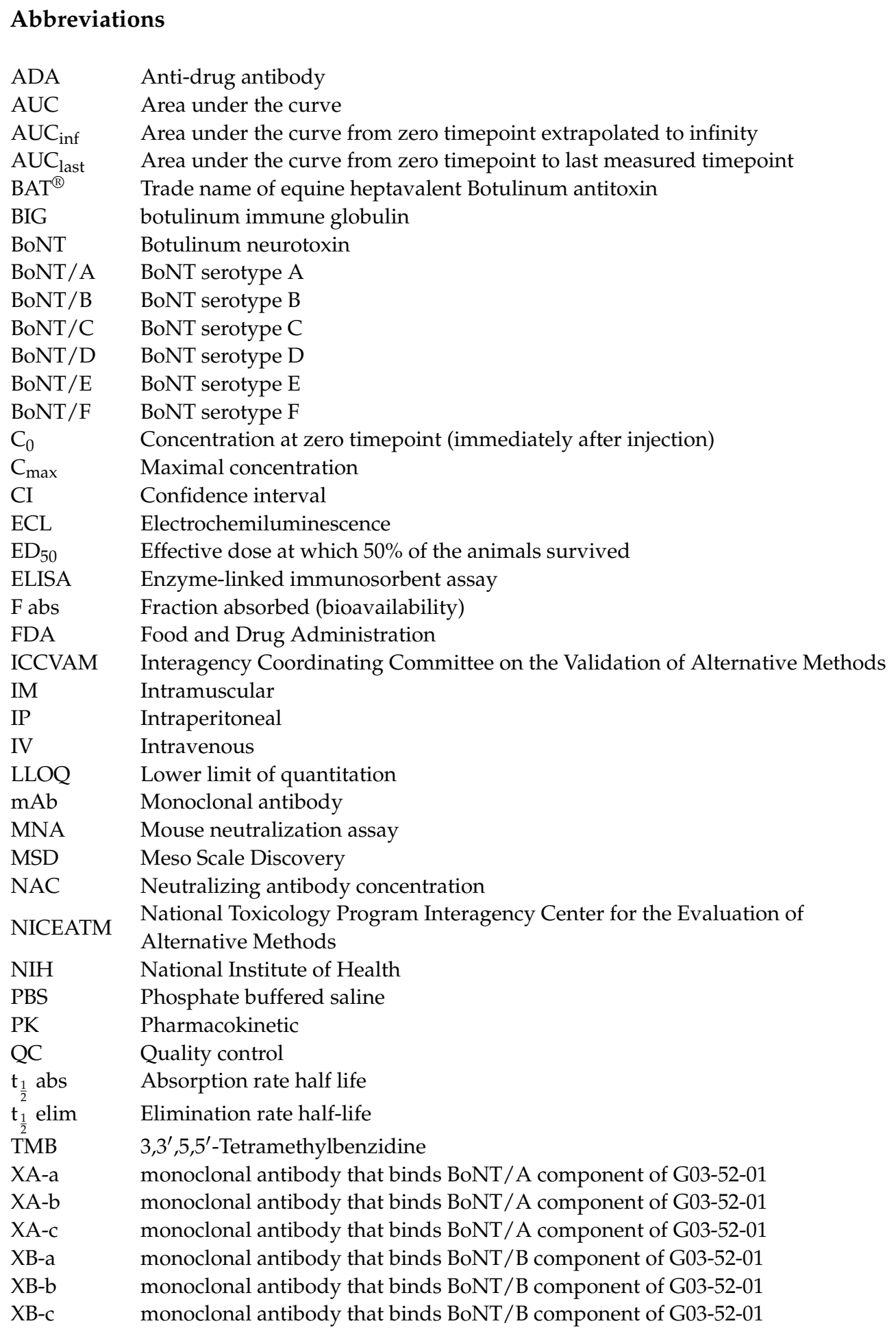

\section{References}

1. Gupta, A.; Sumner, C.J.; Castor, M.; Maslanka, S.; Sobel, J. Adult botulism type F in the United States, 1981-2002. Neurology 2005, 65, 1694-1700. [CrossRef] [PubMed]

2. Hibbs, R.G.; Weber, J.T.; Corwin, A.; Allos, B.M.; El Rehim, M.S.A.; Sharkawy, S.E.; Sarn, J.E.; McKee, K.T., Jr. Experience with the use of an investigational $\mathrm{F}\left(\mathrm{ab}^{\prime}\right) 2$ heptavalent botulism immune globulin of equine origin during an outbreak of type $\mathrm{E}$ botulism in Egypt. Clin. Infect. Dis. 1996, 23, 337-340. [CrossRef]

3. Jalava, K.; Selby, K.; Pihlajasaari, A.; Kolho, E.; Dahlsten, E.; Forss, N.; Backlund, T.; Korkeala, H.; Honkanen-Buzalski, T.; Hulkko, T.; et al. Two cases of food-borne botulism in Finland caused by conserved olives, October 2011. Eurosurveillance 2011, 16, 20034. [CrossRef] [PubMed] 
4. Pingeon, J.M.; Vanbockstael, C.; Popoff, M.R.; King, L.A.; Deschamps, B.; Pradel, G.; Dupont, H.; Spanjaard, A.; Houdard, A.; Mazuet, C.; et al. Two outbreaks of botulism associated with consumption of green olive paste, France, September 2011. Eurosurveillance 2011, 16, 20035. [CrossRef] [PubMed]

5. Gill, D.M. Bacterial toxins: A table of lethal amounts. Microbiol. Rev. 1982, 46, 86-94. [CrossRef] [PubMed]

6. Schechter, R.; Arnon, S.S. Extreme potency of botulinum toxin. Lancet 2000, 355, 237-238. [CrossRef]

7. Lacy, D.B.; Stevens, R.C. Sequence homology and structural analysis of the clostridial neurotoxins. J. Mol. Biol. 1999, 291, 1091-1104. [CrossRef]

8. Hatheway, C.L. Toxigenic clostridia. Clin. Microbiol. Rev. 1990, 3, 66-98. [CrossRef] [PubMed]

9. Hatheway, C.L. Clostridium botulinum and other clostridia that produce botulinum neurotoxin. In Ecology and Control in Foods; Hauschild, A.H.W.D., Karen, L., Eds.; Marcel Dekker: New York, NY, USA, 1993; pp. 3-20.

10. Barash, J.R.; Arnon, S.S. A novel strain of Clostridium botulinum that produces type B and type H botulinum toxins. J. Infect. Dis. 2014, 209, 183-191. [CrossRef] [PubMed]

11. Maslanka, S.E.; Lúquez, C.; Dykes, J.K.; Tepp, W.H.; Pier, C.L.; Pellett, S.; Raphael, B.H.; Kalb, S.R.; Barr, J.R.; Rao, A. A novel botulinum neurotoxin, previously reported as serotype $\mathrm{H}$, has a hybrid-like structure with regions of similarity to the structures of serotypes A and F and is neutralized with serotype A antitoxin. J. Infect. Dis. 2016, 213, 379-385. [CrossRef] [PubMed]

12. Moller, V.; Scheibel, I. Preliminary report on the isolation of an apparently new type of CI. botulinum. Acta Pathol. Microbiol. Scand. 1960, 48, 80. [CrossRef]

13. Arnon, S.S.; Schechter, R.; Inglesby, T.V.; Henderson, D.A.; Bartlett, J.G.; Ascher, M.S.; Eitzen, E.; Fine, A.D.; Hauer, J.; Layton, M.; et al. Botulinum toxin as a biological weapon: Medical and public health management. JAMA 2001, 285, 1059-1070. [CrossRef]

14. Dembek, Z.F.; Smith, L.A.; Rusnak, J.M. Botulism: Cause, effects, diagnosis, clinical and laboratory identification, and treatment modalities. Disaster Med. Public Health Prep. 2007, 1, 122-134. [CrossRef]

15. Sobel, J. Botulism. Clin. Infect. Dis. 2005, 41, 1167-1173. [CrossRef]

16. Khouri, J.M.; Motter, R.N.; Arnon, S.S. Safety and immunogenicity of investigational recombinant botulinum vaccine, rBV A/B, in volunteers with pre-existing botulinum toxoid immunity. Vaccine 2018, 36, 2041-2048. [CrossRef]

17. Nowakowski, A.; Wang, C.; Powers, D.B.; Amersdorfer, P.; Smith, T.J.; Montgomery, V.A.; Sheridan, R.; Blake, R.; Smith, L.A.; Marks, J.D. Potent neutralization of botulinum neurotoxin by recombinant oligoclonal antibody. Proc. Natl. Acad. Sci. USA 2002, 99, 11346-11350. [CrossRef] [PubMed]

18. Fan, Y.; Dong, J.; Lou, J.; Wen, W.; Conrad, F.; Geren, I.N.; Garcia-Rodriguez, C.; Smith, T.J.; Smith, L.A.; Ho, M. Monoclonal antibodies that inhibit the proteolytic activity of botulinum neurotoxin serotype/B. Toxins 2015, 7, 3405-3423. [CrossRef] [PubMed]

19. Garcia-Rodriguez, C.; Razai, A.; Geren, I.N.; Lou, J.; Conrad, F.; Wen, W.H.; Farr-Jones, S.; Smith, T.J.; Brown, J.L.; Skerry, J.C.; et al. A Three Monoclonal Antibody Combination Potently Neutralizes Multiple Botulinum Neurotoxin Serotype E Subtypes. Toxins 2018, 10, 105. [CrossRef]

20. Fan, Y.; Garcia-Rodriguez, C.; Lou, J.; Wen, W.; Conrad, F.; Zhai, W.; Smith, T.J.; Smith, L.A.; Marks, J.D. A three monoclonal antibody combination potently neutralizes multiple botulinum neurotoxin serotype F subtypes. PLoS ONE 2017, 12, e0174187. [CrossRef] [PubMed]

21. Marks, J.D. Deciphering antibody properties that lead to potent botulinum neurotoxin neutralization. Mov. Disord. Off. J. Mov. Disord. Soc. 2004, 19, S101-S108. [CrossRef]

22. Rasetti-Escargueil, C.; Avril, A.; Miethe, S.; Mazuet, C.; Derman, Y.; Selby, K.; Thullier, P.; Pelat, T.; Urbain, R.; Fontayne, A. The european AntibotABE framework program and its update: Development of innovative botulinum antibodies. Toxins 2017, 9, 309. [CrossRef]

23. Casadevall, A. Passive antibody administration (immediate immunity) as a specific defense against biological weapons. Emerg. Infect. Dis. 2002, 8, 833. [CrossRef] [PubMed]

24. Meng, Q.; Garcia-Rodriguez, C.; Manzanarez, G.; Silberg, M.A.; Conrad, F.; Bettencourt, J.; Pan, X.; Breece, T.; To, R.; Li, M.; et al. Engineered domain-based assays to identify individual antibodies in oligoclonal combinations targeting the same protein. Anal. Biochem. 2012, 430, 141-150. [CrossRef] [PubMed]

25. Meng, Q.; Li, M.; Silberg, M.A.; Conrad, F.; Bettencourt, J.; To, R.; Huang, C.; Ma, J.; Meyer, K.; Shimizu, R.; et al. Domain-based assays of individual antibody concentrations in an oligoclonal combination targeting a single protein. Anal. Biochem. 2012, 421, 351-361. [CrossRef] [PubMed]

26. Tomic, M.T.; Espinoza, Y.; Martinez, Z.; Pham, K.; Cobb, R.R.; Snow, D.M.; Earnhart, C.G.; Pals, T.; Syar, E.E.; Niemuth, N.; et al. Monclonal antibody combinations prevent serotype A and serotype B inhalational botulism in a guinea pig model. Toxins 2019, 11, 208. [CrossRef] [PubMed]

27. Nayak, S.U.; Griffiss, J.M.; McKenzie, R.; Fuchs, E.J.; Jurao, R.A.; An, A.T.; Ahene, A.; Tomic, M.; Hendrix, C.W.; Zenilman, J.M. Safety and pharmacokinetics of XOMA $3 \mathrm{AB}$, a novel mixture of three monoclonal antibodies against botulinum toxin A. Antimicrob. Agents Chemother. 2014, 58, 5047-5053. [CrossRef] [PubMed]

28. Guptill, J.; Raja, S.; Juel, V.; Walter, E.; Cohen-Wolkowiez, M.; Hill, H.; Sendra, E.; Hauser, B.; Jackson, P.; Swamy, G. Safety, Tolerability and Pharmacokinetics of NTM-1632, a Novel Mixture of Three Monoclonal Antibodies against Botulinum Toxin B. Antimicrob. Agents Chemother. 2021, 65, e0232920. [CrossRef] 
29. Snow, D.M.; Riling, K.; Kimbler, A.; Espinoza, Y.; Wong, D.; Pham, K.; Martinez, Z.; Kraus, C.N.; Conrad, F.; Garcia-Rodriguez, C.; et al. Safety and Pharmacokinetics of a Four Monoclonal Antibody Combination Against Botulinum C and D Neurotoxins. Antimicrob. Agents Chemother. 2019, 63, e01270-19. [CrossRef]

30. Franz, D.R.; Pitt, L.M.; Clayton, M.A.; Hanes, M.A.; Rose, K.J. Efficacy of prophylactic and therapeutic administration of antitoxin for inhalation botulism. In Botulinum and Tetanus Neurotoxins; Springer: New York, NY, USA, 1993; pp. 473-476.

31. Gelzleichter, T.; Myers, M.; Menton, R.; Niemuth, N.; Matthews, M.; Langford, M. Protection against botulinum toxins provided by passive immunization with botulinum human immune globulin: Evaluation using an inhalation model. J. Appl. Toxicol. 1999, 19, S35-S38. [CrossRef]

32. Interagency Coordinating Committee on the Validation of Alternative Methods. Report on the ICCVAM-NICEATM/ECVAM Scientific Workshop on Alternative Methods to Refine, Reduce, or Replace the Mouse LD50 Assay for Botulinum Toxin Testing. Available online: https://ntp.niehs.nih.gov/iccvam/docs/biologics-docs/bontwkshprept.pdf (accessed on 7 June 2021).

33. Törnqvist, E.; Annas, A.; Granath, B.; Jalkesten, E.; Cotgreave, I.; Öberg, M. Strategic focus on 3R principles reveals major reductions in the use of animals in pharmaceutical toxicity testing. PLoS ONE 2014, 9, e101638. [CrossRef]

34. Shapiro, R.L.; Hatheway, C.; Swerdlow, D.L. Botulism in the United States: A clinical and epidemiologic review. Ann. Intern. Med. 1998, 129, 221-228. [CrossRef]

35. Barker, D.; Gillum, K.T.; Niemuth, N.A.; Kodihalli, S. Therapeutic efficacy of equine botulism heptavalent antitoxin against all seven botulinum neurotoxins in symptomatic guinea pigs. PLoS ONE 2019, 14, e0222670. [CrossRef]

36. Emanuel, A.; Qiu, H.; Barker, D.; Takla, T.; Gillum, K.; Neimuth, N.; Kodihalli, S. Efficacy of equine botulism antitoxin in botulism poisoning in a guinea pig model. PLoS ONE 2019, 14, e0209019. [CrossRef] [PubMed]

37. Kodihalli, S.; Emanuel, A.; Takla, T.; Hua, Y.; Hobbs, C.; LeClaire, R.; O’Donnell, D.C. Therapeutic efficacy of equine botulism antitoxin in Rhesus macaques. PLoS ONE 2017, 12, e0186892. [CrossRef] [PubMed]

38. Arnon, S.S.; Schechter, R.; Maslanka, S.E.; Jewell, N.P.; Hatheway, C.L. Human Botulism Immune Globulin for the Treatment of Infant Botulism. N. Engl. J. Med. 2006, 354, 462-471. [CrossRef]

39. Cangene Corp. BAT®[Botulism Antitoxin Heptavalent (A, B, C, D, E, F, G)—(Equine)] Sterile Solution for Injection. Available online: https: / / www.fda.gov/vaccines-blood-biologics/approved-blood-products/bat-botulism-antitoxin-heptavalent-b-cd-e-f-g-equine (accessed on 16 September 2021).

40. Jankovic, J.; Brin, M.F. Therapeutic uses of botulinum toxin. N. Engl. J. Med. 1991, 324, 1186-1194. [PubMed]

41. Yu, P.A.; Lin, N.H.; Mahon, B.E.; Sobel, J.; Yu, Y.; Mody, R.K.; Gu, W.; Clements, J.; Kim, H.J.; Rao, A.K. Safety and Improved Clinical Outcomes in Patients Treated With New Equine-Derived Heptavalent Botulinum Antitoxin. Clin. Infect. Dis. 2017, 66, S57-S64. [CrossRef]

42. Centers for Disease Control and Prevention, Botulism in the United States. In 1899-1996: Handbook for Epidemiologists, Clinicians, and Laboratory Workers; Centers for Disease Control and Prevention: Atlanta, GA, USA, 1998.

43. Espinoza, Y.; Wong, D.; Ahene, A.; Der, K.; Martinez, Z.; Pham, J.; Cobb, R.R.; Farr-Jones, S.; Marks, J.; Tomic, M.T. Pharmacokinetics of human recombinant anti-botulinum toxin antibodies in rats. Toxins 2019, 11, 345. [CrossRef]

44. Snow, D.M.; Cobb, R.R.; Martinez, J.; Finger-Baker, I.; Collins, L.; Terpening, S.; Syar, E.S.; Niemuth, N.; Kobs, D.; Barnewall, R.; et al. A monoclonal antibody combination against both serotypes $\mathrm{A}$ and $\mathrm{B}$ botulinum toxin prevents inhalational botulism in a guinea pig model. Toxins 2021, 13,31. [CrossRef]

45. USDA. Available online: https://www.nal.usda.gov/awic/institutional-animal-care-and-use-committees (accessed on 16 November 2020).

46. Cardella, M.A. Botulism: Proceedings of a Symposium; U.S Department of Health, Education, Welfare, Public Service: Cincinnati, OH, USA, 1964.

47. Hatheway, C.; Dang, C. Immunogenicity of the neurotoxins of Clostridium botulinum. In Therapy with Botulinum Toxin; Jankovic, J., Hallett, M., Eds.; Marcel Dekker: New York, NY, USA, 1994; Volume 25, pp. 93-107. 